\title{
Transforming failure into success through organisational learning: an analysis of a manufacturing information system
}

\author{
Z Irani $^{1}$, AM Sharif ${ }^{2}$ and PED Love ${ }^{3}$ \\ ${ }^{1}$ Information Systems Evaluation and Integration Group (ISEIG), Department of Information Systems and Computing, Brunel \\ University, Uxbridge, Middlesex, UB8 3PH, UK; ${ }^{2} \mathrm{KPMG}$ Consulting, 8 Salisbury Square, London, EC4Y 8BB, UK; ${ }^{3}$ School of \\ Architecture and Building, Deakin University, Geelong, Victoria, Australia
}

\begin{abstract}
This paper describes the idiosyncracies of a case study company, through highlighting issues and problems experienced during their attempts to evaluate, implement and realise the holistic implications of a manufacturing information system. Although the Information System (IS) was operational for a period of time, it was eventually deemed a failure. The reason for this was that a range of human and organisational factors prevented the organisation from embracing the full impact of the system. The eventual success of their information system was realised through a bespoke implementation, based upon a traditional systems development lifecycle that indirectly addressed learning issues following the earlier failed deployment. The paper highlights key issues relating to business success and failure, and then contrasts them alongside the presented case study. In doing so, the authors conclude by proposing methods through which manufacturing information systems can be transformed for business success. This is described achievable through both a realisation in the positioning of the organisation relative to technology management, and the related mapping of human and technological constructs that support information systems related success. European Journal of Information Systems (2001) 10, 55-66.
\end{abstract}

\section{Introduction}

The normative literature regards innovative strategies as being reliant upon creative thinking and management, together with the ability to plan/react to customer-related change. Such are considered key enablers for organisational growth and success. Organisations that focus on technology are particularly prone to encountering change rapidly. Carrier (1999) points out, that the management of such firms is becoming increasingly reliant upon managing either disruptive technology (technology that replaces processes) or creative technology (technology that enhances processes). Clearly, this can cause a dichotomy in how organisations operate and embrace IT-enabled change.

To overcome such obstacles, Brown and Eisenhardt (1998) suggest that organisations should develop competitive strategies that focus on:

- thriving on uncertainty;

- discovery and reinvention;

- maintenance of a broad vision;

- market realignment;

- creative thought and requirement satisfaction;

- realignment of disruptive to creative technology; and

- the planning for learning (plan for failure).

Tuval (1999) highlights similar issues, but, suggests organisations target key stakeholders within the enterprise, as well as their customers. In doing so, realising the potential for change within the expectation of each stakeholder, together with establishing how such expectations can be leveraged through organisational change. Hence, stakeholder power and influence need to be seen as highly important Critical Success Factors (CSF) that will continue to drive improvements in structure, culture and process (Rockart, 1979; Mercer, 1999). All of these issues seek to sustain the organisation's capability to learn and adapt to problems as they arise, thus establishing a method to operationalise the fundamental characteristics of a learning organisation (KPMG, 1996).

In order to draw on the issues of IT-enabled change and its contribution towards transformation, a case study is used to gain an understanding about why and how a small-medium-sized manufacturing enterprise (known as Company V) learned from failure with respect to the implementation of an information system.

The case study adopted a vendor-based Manufacturing Resource Planning (MRPII) information system (Wight, 1984), which subsequently failed to satisfy the requirements of its internal stakeholders.

The reason for this failure is attributed to not considering human and organisational factors during the evaluation and implementation process. However, in later realising the importance of such issues, the company sought to address what later became regarded as constructs for success, through undertaking a process of bespoke information system development. 
Such constructs for success have been extrapolated from the case study, and are presented within technology management taxonomies. In doing so, this allows others to draw parallels through providing a validated 'frame of reference'. The organisation's experiences, in solving the problems associated with the implementation of their information system, provide a learning opportunity for those companies that are seeking a competitive advantage through technology management.

\section{Information systems failure}

Despite the substantial financial commitment budgeted to the information systems function, many companies continue to express their discontent with the performance of their information systems. In support of this, Hochstrasser and Griffiths (1991) report that 70\% of IS projects fail to deliver the benefits sought, and in many cases, provide no measurable gains at all.

Although information systems failure is regarded as widespread, there remains no common frame of reference regarding the constituent components of a failure, with Keil (1994) contending that the definition of failure depends on whom you ask. Consequently, the literature is somewhat vague on the actual percentage of projects that fail. DeMarco (1982) suggests that there is a $15 \%$ failure rate with IS projects, although this would appear somewhat optimistic, as Lyytinen and Hirschheim (1987) and then Crescenzi (1989) report failure rates of $60 \%$ and $85 \%$ respectively. More recently, Phan et al (1995) presented the results of a survey that showed $25 \%$ of the 143 projects surveyed did not meet user requirements. In the same year, Johnson (1995) reported survey results that showed from a sample of 365 companies, $31 \%$ were cancelled before completion, and $53 \%$ overran, with overrun costs and budget impairing functionality. Consequently, the claim made by Remenyi (1991) that there are as many failed information systems implementations as there are successful ones appears to remain valid. However, failed systems are costly, not only for hardware and software but, also in human and organisational terms (Irani \& Love, 2000). However, in trying to learn from past failures, Willcocks and Margetts (1994) suggest that project planning estimates and management tend to improve with greater information systems experience.

In spite of disappointments in information system investments, successful deployments can bring many advantages that include enhanced efficiency and effectiveness through business process transformation. Willcocks (1994) points out that successful users of information systems are those that:

- continuously measure and control their systems effectiveness, possibly a result of their learning experiences of being able to identify where project implications arise; and,
- appropriately manage contentious human and organisational factors.

\section{Company experience: learning opportunity}

The case study presented is used to describe a company's experiences in addressing the problems associated with adopting a manufacturing information system. The paper offers a learning opportunity for other Small/Medium Enterprises (SME) that are using information systems to support IT-enabled business transformational change.

\section{Research methodology}

Previous research suggests that an organisation's failure with information systems is primarily attributable to not meeting user expectations, which underlines the significance of the soft human and organisational issues involved with information systems (Irani \& Love, 2000; Khalifa et al, 2000). Consequently, there was a need for a methodology that would involve and enfranchise an organisation and their staff so that knowledge about information systems evaluation and implementation could be derived to develop technology management taxonomies, thus supporting organisational self-evaluation. Considering the originality of this research a case study approach was adopted (Bonoma, 1985; Hakim, 1987; Yin, 1994; Irani et al, 1999). The case study described through this research was not systematically sampled, therefore, it is not possible to generalise the findings to a wider population of SMEs with similar characteristics within the manufacturing industry. Analytical generalisations are however drawn and technology management taxonomies for evaluation are propagated for use by other SMEs in the manufacturing industry.

\section{Data collection and analysis}

A fieldwork case study can be used to collect both quantitative and qualitative data, although the research methods employed during this investigation were qualitative. Structured interviews were used as the primary research instrument with data being triangulated through interviews and discussions with senior management and shop-floor employees.

Senior management were formally interviewed with a semi-structured interview agenda being used to navigate and guide the interview process. More informal methods were used to elicit data from shop floor employees. These methods of data gathering were justified as they allowed the researcher to ask standardised questions of the interviewee, and 'steer' the interview process. All interviews were tape recorded and later transcribed. 


\section{Evaluation process}

The success of Company V's previous information system investments helped to give them encouragement and motivation, which they needed to introduce a computerized Production Planning and Control (PPC) information system (the genesis of MRPII). However, unlike other 'smaller' investments, the driving force behind this project was from the Managing Director (MD), who sanctioned all investment decisions. When asked to evaluate the perceived impact of the proposed PPC system, the MD replied:

The scope of benefits from investing in information technology appeared enormous, ... only been restricted by my imagination. I was the main visionary leader and could see the longterm strategic implications of my decision to invest. ... I was sure the benefits would far outweigh the costs.

However, there appeared to be other factors 'driving' this investment, with the MD saying:

We were under significant pressure by our customers to offer year on year cost reductions... so there were risks associated with not utilising new technology to provide a competitive advantage.

Company V lacked a robust evaluation system, which would appear to be rooted in their lack of previous investment appraisal in projects that could not be appraised using traditional techniques, a taxonomy of which is offered by Irani et al (1997). The adoption of MRPII initially presented the company with a dilemma. In particular, strategic benefits such as: perceived market leadership, leader in new technology, promotion of an open culture, etc, albeit extremely important for the growth and survival of the firm, were not readily convertible into cash values. Consequently, traditional appraisal techniques proved inadequate for the changing nature of benefits resulting from Company V's capital expenditure.

Previous investments in Numerically Controlled (NC)/Computer Numerically Controlled (CNC) equipment had been financed through loan agreements, where cash flow projections and sensitivity analysis had been used to assess the financial impact and risk of the investment. However, Company V soon discovered that such accountancy frameworks were not suitable for investments with intangible and non-financial benefits, therefore proving inappropriate for the evaluation of their proposed information system.

These issues, together with a new and inexperienced management team, unaware of strategic and integrated appraisal techniques that could acknowledge, albeit subjectively, qualitative costs and benefits, resulted in a simplistic Cost/Benefit Analysis (CBA) being used. Management's use of CBA, allowed the listing of perceived project benefits and costs, however, no assign- ments of financial values were made to those factors identified. The reason for this was due to the complexity, subjectivity and time-consuming nature of identifying and assigning arbitrary values to the intangible and nonfinancial benefits. Although the appraisal method used was subjective and judgemental, Company V employed much time and effort into identifying the range of benefits associated with the proposed investment. The taxonomy of benefits identified as part of Company V's CBA can be seen in Figure 1.

This taxonomy has been categorised into three: strategic, tactical, and operational. Regarding the costs considered as part of Company V's CBA, they only identified direct financial costs, such as those presented by Irani et al (1997; 1998). Hence, as Company V was unable to accurately calculate the financial returns achievable, an 'act of faith' decision to invest in their MRPII system was made by senior management. Interestingly enough, the British Chartered Institute of Management Accountants/Institute of Production Engineers (British CIMA/IProdE, 1987), have suggested that some benefits of information systems cannot be quantified, and state that 'investing. . . as an act of faith on such systems, may be required'. Therefore, the British CIMA/IProdE appears to advocate the justification strategy adopted by Company V. However, Kaplan (1985) explains that if companies, even for good strategic reasons, consistently invest in projects whose financial returns are unknown, or below their cost of capital, they will inevitably begin to approach insolvency. Therefore the authors suggest that much care needs to be taken during the evaluation of information systems.

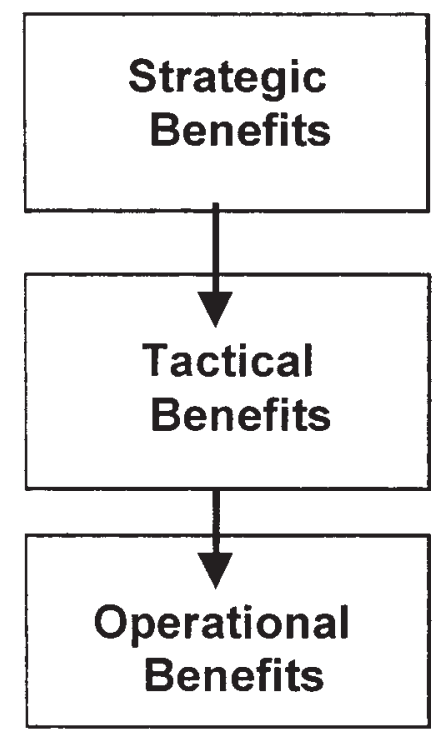

Figure 1 The taxonomy of strategic, tactical and operational benefits. 


\section{Vendor package implementation}

\section{Software selection and development}

The core PPC software module bought and installed was the Production Control and Scheduling (PCS) function. Additional functions were also considered by the system selection and implementation team at the company but later rejected. The basis for their decision to reject these additional modules centred on poor user interface, high cost, repetitive data entry and perceived poor effectiveness in the planning and controlling of jobbing shop production.

The system selection and implementation team did however identify a need for a tool management module, which was later purchased from a secondary software vendor. During the implementation of the core PCS module, it became evident that the vendor-supplied software system required the user to fulfil the 'needs' of the module, hindering the effective representation of Company V's data. As such, issues involved with the redesigning of business processes (such as these) were sought to be avoided, thus limiting further expense, time and disruptions to production performance. Furthermore, these implications appeared as significant cost factors that had not been acknowledged within their previous CBA. Nonetheless, the redesign of processes presented themselves to Company $\mathrm{V}$ as unavoidable, to achieve the necessary functionality for the effective use of the PCS module.

For numerous other reasons (human and organisational), the introduction of the information system proved more difficult than anticipated. For the first time, Company V had disciplines, controls and procedures, with their information system producing route cards and operational planning. Clearly, supporting traceability that the company sought as a competitive advantage in light of quality standards such as British Standard 5750, the organisation was dependent on accurate reliable data being generated to produce information for management.

Employee resistance towards computerised information systems proved to be a contributing factor towards the complexity of implementation. People openly blamed the information system when things went wrong. The production director was regularly confronted with 'work to lists' that had enormous amounts of seemingly meaningless data, and was ready to dismiss the system and go back to the old manual way of PPC. Yet, the software selection and implementation team managed to convince the production director that computerised PPC was the only way forward. The team explained that the difficulties being experienced could be attributable to the lack of a suitable reporting structure and data format. Furthermore, they explained that the system needed time to 'settle down', and was the only way forward if the company's expansion plans for growth based on efficient and effective IT-enabled business processes were to be achieved.

Company V's biggest problem was with their vendor PCS module, which only worked efficiently if supplied with a continuous flow of 'clean' data. However, if there were any 'hitches' in data recording, or accuracy, then the system became highly unstable. Therefore, the need to alleviate this problem led the selection and implementation team to investigate the purchase of a vendor Shop Floor Data Collection (SFDC) module as a 'plug-in'. Further benefits resulting from such an investment were considered to include improvements in the accuracy with which PPC resource decisions could be made by management and empowered employees. Moreover, the purchase of the SFDC module seemed a natural progression towards achieving 'full' MRPII (intra-organisational) information system integration.

\section{Human and organisational issues}

In hindsight, the software selection and implementation team regretted not educating the workforce on the operational need for PPC. Furthermore, management attributed this lack of education and training towards the system not receiving the operational support necessary for its successful implementation and operation, for example, resulting in unreliable data reflected in the form of 'noise' in the Master Production Schedule (MPS). The consequence of 'noise' in the MPS led to additional operational costs, decreases in productivity, and loss of customer base following inaccurate delivery lead-times being quoted. All these factors had a significant impact on the perceived success of the SFDC module, and were not acknowledged as implementation issues during the evaluation process.

It was at this point that the MD, who was considered to be the project champion, turned his attention to a new project, appearing to have either lost interest, due to the lack of success, or been 'driven' by other organisational improvement initiatives. Responsibility of the implementation process was delegated to others, and it was envisaged that the well-established production director would take up the challenge. Interestingly, the production director was not a key member of the software selection and implementation team, but instead operated as an honoree, and on occasion simply advised on technical issues but only when consulted. The production director was therefore expected to take the lead in his role as head of the production department. This new responsibility for ensuring project success of a 'half' implemented information system, for which little consultation with the production director had been sought, was not readily welcomed. However, the production director did acknowledge the contribution the PPC system was making/could further make towards the streamlining of the production function by stating: 
It was never my project. No one wanted to involve me. . .So I didn't want to get involved in it (the production planning and control system), even more so, when it was proving not to deliver the benefits sought.

It is clear that the focus of the software selection and implementation team suddenly changed, from one of great expectation, to a process of blame apportioning, which is described by Barker (1998). Many of the problems that 'real-time' shop floor data collection were intended to alleviate appeared to further complicate this technology. The production director, in his defence, claimed that the failure of the SFDC module was because:

We had not sat down in the first place and formalised our systems. . .People were not informed of the impact the system would make on their job function(s). . nobody on the shop floor bought into ensuring the success of the system. . . They needed educating.

\section{Identifying failure within the implementation process} It appeared that at this point in the implementation process, the software selection and implementation team reached a 'stalemate'. No clear direction could be decided, as there was no focused leadership within the team. Furthermore, the PPC software appeared to be dictating the need for specialised functions, such as data analysis and manipulation, and control of the production function. This was not welcomed by the majority of the management team, who were trying to develop a corporate culture based on openness, through promoting the concepts of flexible, empowered teamwork.

The adoption of the information system did not have the operational support necessary for its successful use. As a result, management, who were supported by the software selection and implementation team, advocated the development of a bespoke system that was considered more suited to the perceived idiosyncracies of the company's business processes, together with their perceived unique needs as a subcontract jobbing shop.

Longenecker et al (1999) offers a contrast on failing to achieve information systems implementation, with Table 1 culminating research with that extrapolated from Company V.

The interpretation of Table 1 would appear to support the argument that the appropriate management of intangible, qualitative, people-focussed factors can be used as enablers for success or failure. Hence, as such, the empirical findings support the argument that new technology alone does not imply business success but relies heavily on the input of vested stakeholders.

\section{Bespoke development of an information system $^{1}$}

Driven by the need to develop an 'integrated' information system that would acknowledge the idiosyncra-

Table 1 Aspects of business failure and success within Company $\mathrm{V}$

\begin{tabular}{ll}
\hline Issues found in Company $V$ & $\begin{array}{l}\text { Constructs } \\
\text { for failure for success }\end{array}$ \\
\hline
\end{tabular}

Bilateral communication

Planning

'Voice' for front-line managers

Direction and planning

Management development

Motivation

Culture and feedback

Operating structure

Cashflow

Workforce-management conflicts

Communication

Improvement of leadership

Training and motivation

Application of corrective action

Clear goal definition

Change management

Goal conflict

Teamwork

Customer service

Empowering managers

Performance indicators

Total quality management

Resources

Organisational learning

Product development

Stakeholder support

Technology management

Standards and regulations

4

4

4

4

4

4

4

4

4

4

4

4
4
4
4
4
4
4
4
4
4
4
4
4
4
4
4
4

Source: Adapted from Longenecker et al (1999).

cies of Company $\mathrm{V}$, the firm set about developing their 'own' business solution. The previously formed software selection and implementation team took the initiative and developed a business case for a bespoke information system.

The company believed that it would be more satisfied with the results of their 'own' system, rather than the on-going implementation of what was increasingly becoming a 'rigid' vendor system. The development of bespoke software was perceived to give Company $\mathrm{V}$ a 'new' opportunity to gain operational support that was considered necessary for success. Hence, it would appear that human and organisational issues played a crucial part in this decision making process.

The decision by Company V to develop its 'own' software was seen as a significant turnaround by many within the organisation, and indeed contradicted the MD's initial justification for purchasing vendor software. The scope of costs associated with developing a bespoke information system was considered greater than those detailed during the original CBA. Therefore, as part of a revised CBA, Company V identified a new dimension of costs that it perceived would be incurred during the development, implementation and operation of a bespoke infor- 


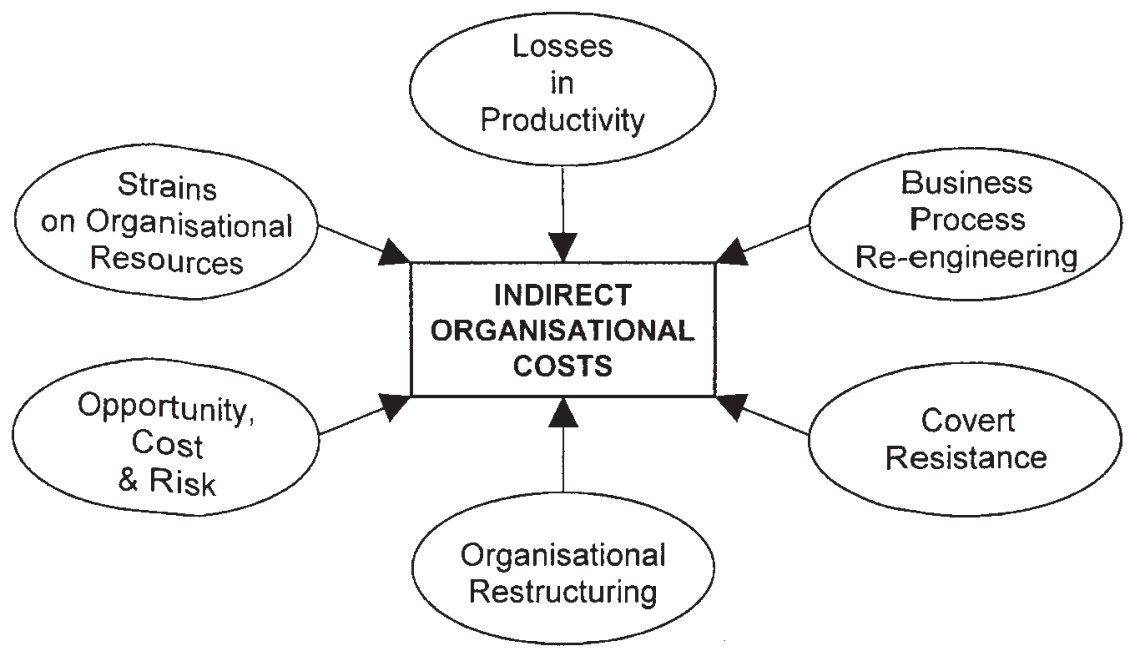

Figure 2 Taxonomy of indirect organisational costs.

mation system. These new costs were considered additional to the already realised direct costs that had been incurred during the earlier purchase of vendor software. Figures 2 and 3 present taxonomies that have been classified as indirect organisational and human costs.

Incidentally, the majority of benefits originally envisaged as deliverables from implementing vendor software appeared to have still remained relevant. Acknowledging that the vendor SFDC system had significant problems and as such, failed to realise expectation, Company $\mathrm{V}$ decided to abandon its use. This decision was justified by:

- poor data reliability;

- network interface problems;

- swipe hardware terminal problems;

- lack of employee support and discipline to use consistently the bar code system;

- lack of interest to continue the implementation process;
- manipulation of system (staff failing to use the system; staff falsifying records);

- misalignment between the strategic direction of the vendor and the organisation;

- falls in productivity; and

- lack of clear project focus, leadership and deliverables.

It was decided by the MD to enlist the support of a consultant, as help was needed to facilitate the design, development and implementation of the bespoke information system.

However, before such processes commenced, Company $\mathrm{V}$ re-assessed its strategic direction, strengths and weaknesses, and revised its business plan together with developing a project strategy and plan. Company V then began a series of intensive education sessions with managers, as well as workshop training days with operational employees. All functional managers were educated on the

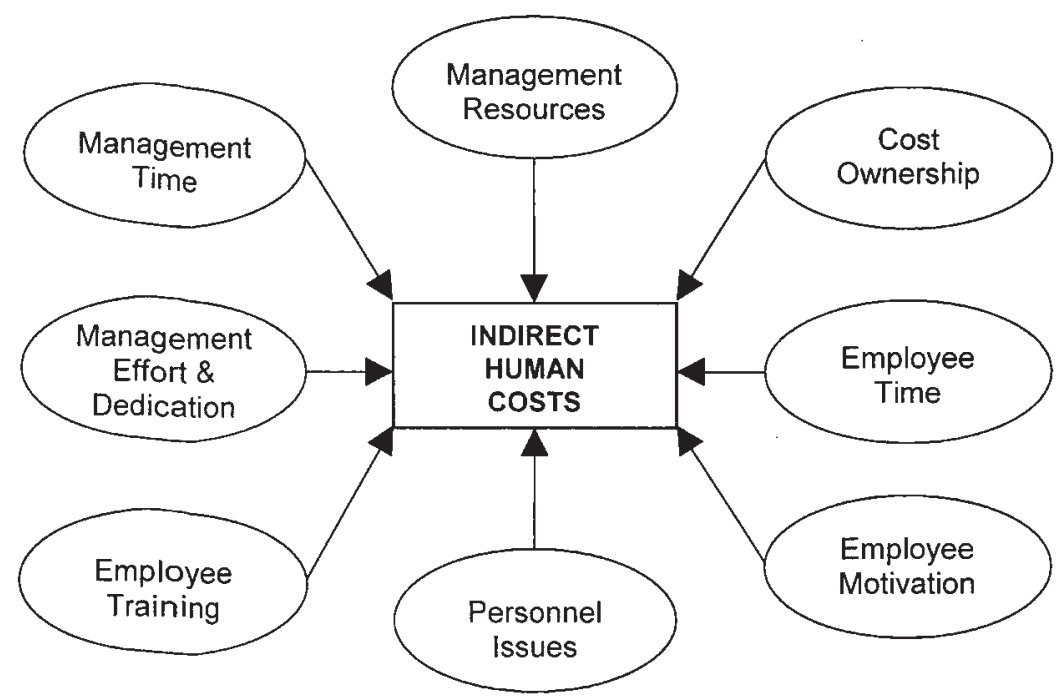

Figure 3 Taxonomy of indirect human costs. 
importance of an integrated manufacturing information system, and on the impact that the investment would make to their job function(s). A simplified concept justification course was developed and delivered to shopfloor stakeholders. This course not only addressed the educational issues associated with a manufacturing information system but also looked at the practical implications of such a system on individual job function(s). The subject and teaching media used varied, using as much imagination as possible. Teamwork was promoted with all employees being mixed and grouped together. They were filmed and reviewed playing 'fun to learn' games, using 'Lego' and 'jigsaws', all with meaning for throughput production flow, communication, Just in Time (JIT), inventory management and Total Quality Management (TQM). The workshop exercises appeared to be well received and helped to 'win over' sceptics. In parallel with the workshop training and education sessions, a system design and development team was assembled. Where necessary, new employees (subject to their acceptance) were sent on external training courses to develop new skills (technical). In addition, further resources were employed, usually in the form of software engineers, who were students on industrial placements ${ }^{2}$.

This type of recruitment policy helped to keep system development costs down, thus reducing the need for expensive contract engineers who were considered out of the financial reach of an SME. Furthermore, the legalities of employing new resources were avoided, as the students were on fixed term contracts. An additional benefit of having software engineering, information systems and computer science students on the project was to maintain a constant 'stream' of innovation, inspiration and motivation. However, much management and control was necessary to retain project focus. During the development of the bespoke information system, Company $\mathrm{V}$ schematically mapped out its entire business processes using static business process design tools (Irani et al, 2000). This allowed the redesign of business processes, and facilitated the removal of 'non-value adding' activities. This approach to business transformation was considerably different from earlier attempts, in that previous process redesign efforts appeared to be generic, and were based around the functionality of the vendor supplied software.

The re-engineering of business processes before bespoke system development allowed for the software being developed to be modeled on 'best practice' jobbing shop processes. It was at this point that the expertise of the consultant and academic institutions that supported the placement students proved invaluable. In essence, Company V's business transformation was built on the constructs of 'best practice', together with a review of those features available in 'off the shelf' packages.

\section{Organisational and technological business transformation: a functional model}

\section{The '5M' Model}

The case study findings have identified a number of technology management factors as having an impact on the failure/success of Company V's information system implementation and subsequent business transformation. These factors are presented in Table 2, where their contribution towards the implementation of vendor software and later development of a bespoke system is identified.

Figure 4 presents a validated model of technology management integration constructs extrapolated from the case study.

The authors of the ' $5 \mathrm{M}$ ' model, which also complements the four-stage information technology strategy of Ho (1996), now present these factors. This approach details the primary issues that enable the organisational, strategic and operational aspects of an integrated manufacturing enterprise solution. Each factor in turn constitutes those aspects of the business that are required to support business transformation. Hence, the 5M model can complement performance metrics available to management. This, in turn, may also be realised through conducting a balanced scorecard approach.

\section{Material}

This facet essentially describes the flow of information packets within the organisation, and the management of mission-critical information (in terms of data, process and knowledge). This can be achieved through the adoption of an open information system, and may be supported by a consistent reporting scheme and documentation format ie the generation of an MPS that details appropriate information, such as customer delivery dates, material availability, capacity, schedules etc.

\section{Man}

To realise the full benefit of combining each of these issues together, human and organisational resources should be carefully planned and matched against technological implications. To enable this, it is essential to target the right people to be trained and educated, and for the required level of training resources to be available to them. The culture and management mix of the organisation should also endeavour to encourage goalfocussed aptitude to be an inherent characteristic of each project.

Within Company $\mathrm{V}$, there is an organisational belief that $20 \%$ of the workforce should be capable of 'high' precision manufacture, with the remaining $80 \%$ capable of 'general' sub-contract jobbing shop work. The implications for this are far reaching in terms of human and organisational benefits and costs. 
Table 2 Comparative review of technology management processes

\begin{tabular}{|c|c|c|}
\hline Technology management factors & Vendor software & Bespoke software \\
\hline Investment strategy & Act of faith & Act of faith \\
\hline Formal project management & No project management techniques & Project manager, Gantt charts, procedures \\
\hline Company culture & Closed and reactive & Open and proactive \\
\hline Concept justification to workforce & $\begin{array}{l}\text { No discussion/workforce } \\
\text { involvement }\end{array}$ & $\begin{array}{l}\text { Discussion with workforce on the importance } \\
\text { of MRPII }\end{array}$ \\
\hline Workforce educated and trained & No training/education on IT/MRPII & $\begin{array}{l}\text { Workforce educated about MPRII and IT } \\
\text { trained }\end{array}$ \\
\hline Management educated and trained & $\begin{array}{l}\text { Only project team managers } \\
\text { trained and educated about } \\
\text { IT/MRPII }\end{array}$ & $\begin{array}{l}\text { All organisational managers trained and } \\
\text { educated about IT/MRPII }\end{array}$ \\
\hline Appraisal technique & Cost/benefit analysis & Cost/benefit analysis \\
\hline Consultancy support & No external involvement & Consultancy facilitation \\
\hline Academic involvement & No university involvement & University industrial placement students \\
\hline Continuous project evaluation & No periodic review of project & Monthly management review meetings \\
\hline Investment integrated into business plan & $\begin{array}{l}\text { Investment seen in isolation to } \\
\text { business objectives }\end{array}$ & $\begin{array}{l}\text { Investment integrated into strategic, tactical } \\
\text { and operation business objectives }\end{array}$ \\
\hline Classification of benefits identified & Strategic, tactical and operational & Strategic, tactical and operational \\
\hline Nature of benefits identified & $\begin{array}{l}\text { Financial, non-financial and } \\
\text { intangible }\end{array}$ & Financial, non-financial and intangible \\
\hline Classification of costs identified & Direct costs & $\begin{array}{l}\text { Direct/indirect costs (human and } \\
\text { organisational) }\end{array}$ \\
\hline Nature of costs identified & Financial & Financial and intangible \\
\hline Risk considered & Competitive risk & Competitive risk \\
\hline Perceived project outcome & Failure & Success \\
\hline
\end{tabular}

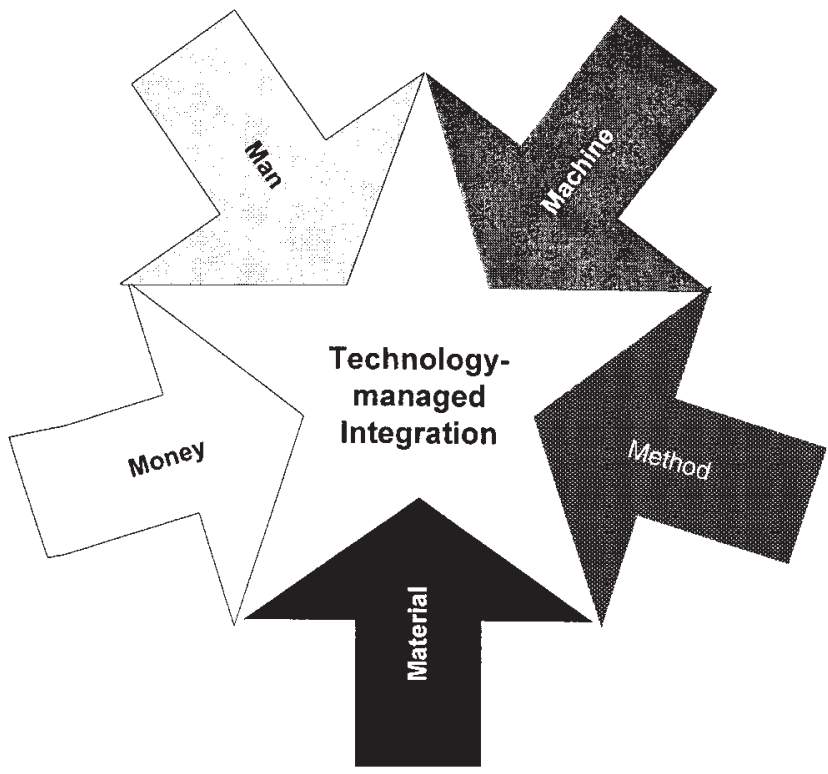

Figure 4 The '5M' evaluation model.

\section{Machine}

The introduction and adoption of new resources, such as information systems, are necessary requirements to maintain competitive advantage, and achieve medium and long-term strategic goals. Investment in appropriate hardware and software is important and issues of integration with proprietary systems, obsolescence and upgradeability should be taken into account when evaluating such technologies. Internal competencies and a posi- tive cultural atmosphere are significant external factors outside the traditional information systems evaluation process. As such, they have the potential to hinder this process (Braglia \& Petroni, 1999).

\section{Money}

Money, or capital expenditure, is the most important factor when considering investing in new technology. The reason for this is that no matter how necessary the technology, if finances do not support its adoption, its justification becomes futile. The implementation of technologies should focus on a long-term commitment from which tactical and strategic benefits can be gained for the organisation. Therefore, judicious and accurate modelling of cash flows is required, wherein indirect costs which need to be considered during the capital budgeting process are considered. Similarly, prudence needs to be exercised when considering strategic and tactical benefits, as operational survival needs to be realised to support medium and long-term growth and success.

\section{Method}

Methods to harness and realise those factors that support successful integration within business processes have to be achieved (ie through structured evaluations). The development of the decision-making process beyond traditionally myopic financial accounting procedures, is a significant step in this direction. Amongst others, those non-economic appraisal techniques identified by Irani et al $(1997$; 1998) may be considered in this light. 
By considering qualitative project implications during the justification process, the wider implications of information, knowledge, human and non-human resources can be put into context.

The Capability Maturity Model (CMM) as described by Paulk et al (1993) has been the genesis for many such transformation approaches, particularly in software engineering. This has been the basis for other cultural management models, such as that proposed by Dale (1993), together with the recent subjective approach of S3's software process improvement project (Kelly \& Culleton, 1999). However, Carrier (1999) warns against the usage of these process maturity models as a purely methodology-driven business 'quick fix'. Indeed, Burnes (1998) agrees with this view also, stating that change need not always be prescriptive, but a combination of changes 'choices', in order to provide stability and focus.

\section{The need for continuous business transformation}

The authors believe, however, that the basis of any forecasted integration lies clearly at the feet of a lifecycle methodology, which will involve many different aspects of an organisation. Hence, this case study would appear to support the normative literature in its view that 'to holistically evaluate information system projects, there is a need to involve team members from each functional group in the assessment, implementation and evaluation of an adopted technology'. This involves listening to employees' comments and embracing change and new ideas through the mechanism of a project management lifecycle model (aspects of which are embedded within the $5 \mathrm{M}$ model). Furthermore, external evaluators should also carry out post-implementation evaluation so that an independent perspective on the project deliverables can be obtained and then integrated into the learning of the organisation.

Table 3 defines those factors that have been identified in the $5 \mathrm{M}$ model arising out of the case study research presented. This table shows the impact of each ' $M$ ' factor on these aspects of the information system in Company $\mathrm{V}$. This matrix defines failure and success of the information system in the case study, and can be used by others as a frame of reference for defining the business fit of manufacturing information systems.

\section{Discussion and concluding comments}

The authors have shown similarities between the characteristics of the case study and previously published research on organisational transformation and change. These characteristics were found to be indicative of business failure. Furthermore, the authors proposed a framework for assessing the qualitative aspects of information system investments in this context.

An evaluative model for assessing the fit of people, process and technology factors was proposed (the $5 \mathrm{M}$ model'). The case study clearly identified human and organisational issues as essential factors for ensuring the successful integration of an information system. The findings from the case study indicate that the evaluation process for implementing a manufacturing information system was not financial in nature; rather, the decision to invest was made as an 'act of faith', although calling it a strategic decision may have been more comforting for management.

The reason for Company V's ad hoc approach to investment evaluation was because many of the benefits resulting from the information system were considered intangible and non-financial, and as a result, could not be accommodated within traditional appraisal frameworks. This was further complicated by the new and inexperienced management team, and their lack of knowledge of hybrid appraisal methods.

However, it is this misguided need by many companies to analyse all investment proposals in financial terms, which presents many problems during project evaluation.

Hence, in broader terms, with management under increasing pressure to produce financial savings, much care needs to be taken to ensure that those projects with long-term strategic focuses are not excluded on the basis of their intangible and non-financial benefits.

The significance of human and organisational factors has been raised within this paper, with their inclusion essential within any robust evaluation process. This is exemplified by the case study, as during the adoption of vendor MRPII modules, no account of 'soft' cost factors (human and organisational) was made. As a result, the system was deemed a failure as it was substantially over

Table 3 Business transformation factors mapped to the $5 \mathrm{M}$ model

\begin{tabular}{|c|c|c|c|c|c|}
\hline Factor & Material & Man & Machine & Money & Method \\
\hline Re-engineering & 4 & 4 & 4 & 4 & 4 \\
\hline Education and training & 4 & 4 & & 4 & 4 \\
\hline Information management & & 4 & & & 4 \\
\hline Package selection & 4 & & & 4 & 4 \\
\hline Change management & & 4 & & & 4 \\
\hline Stakeholders & & 4 & & & 4 \\
\hline
\end{tabular}


Table 4 Learning issues associated with transforming manufacturing IS failure into success

- Organisational culture and infrastructure technology facilitates synergy between people, processes and technology-the proposed '5M model'.

- IT/IS evaluation against qualitative factors, should be part of the change management philosophy in manufacturing organisations: management and workforce buy-in, will underpin, initiate and maintain enterprise growth as a result.

- Business transformation (and hence implementation success), should be through a flexible realisation of the organisation's growth (ie a lifecycle model should exist to model the organisation's learning and change processes).
- Support from management through agile decision making.

- An understanding and successful business fit of the new technology.

- Communication, involvement and development through all levels of the organisation. budget, and not accepted by its stakeholders. However, in later addressing human and organisational issues, the company set about developing a bespoke solution, which is considered to have resulted in the successful 'roll out' of a bespoke solution, based upon addressing both human-organisational and technological issues.

Hence, it would appear that there are three key areas that can be identified as providing enterprises with the capacity to transform themselves from failure to success, along with the respective critical success factors, as shown in Table 4.

These factors attempt to outline, how organisational structures, culture and development should be implicitly linked with the adoption and implementation of any information systems solution. The case study clearly highlights that business transformation is heavily reliant upon both change management and organisational learning.

Indeed, it has been shown that both strategic (external) and operational (internal) CSFs, are reliant upon people and associated Key Performance Indicators (KPIs) to measure the success of business decisions. Such organisations are characterised by their capability to change themselves, by seizing opportunities to grow, reacting to threats and utilising knowledge structures appropriately. This approaches the concept of an agile organisation, which most manufacturing organisations have been attempting to aspire to in recent years.

The transformation of the case study's information system was considered to be due to the realisation of stakeholders. The importance of sponsorship and a 'voice' which represents different stakeholder interests appears to be a valuable asset in driving forward IT enabled change.

Finally, for significant information system initiatives to be successful, it is imperative that the organisational culture is prepared to learn from the previous 'pain' of change. In attempting to facilitate this process, the authors have developed technology management taxonomies for industry.

\section{Notes}

1 This investment was partially funded by two government-sponsored schemes.

2 Students were industrially placed at Company V for a period of 6 months, or 1 year. During their placement each student was supervised by a member of university staff, implicitly resulting in technical support.

Acknowledgements - The authors would like to thank the case study for its participation in this study. Without its cooperation and support from management and employees, the research could not have been undertaken. The statements and opinions in this paper are in all respects those of the author and do not represent the views of KPMG.

The authors are also most grateful to Dr Steve Smithson and the four anonymous referees for their helpful constructive comments, which improved this manuscript through its re-submissions. Finally, the authors would like to acknowledge the financial support provided by the Engineering and Physical Sciences Research Council (EPSRC) Ref: [GR/M95066] and [GR/R08025/01].

\section{References}

BARKER B (1998) The identification of factors affecting change towards best practice in manufacturing organisations. Management Decision 36(8): 549-556.

Bonoma TV (1985) Case research in marketing: opportunities, problems, and a process. Journal of Marketing Research 12: 199-208.

Braglia M and Petroni A (1999) Shortcomings and benefits associated with the implementation of MRP packages: a survey research. Logistics Information Management 12(6): 428-438.
BRITISH CIMA/IProdE (1987) Justifying Investments in Advanced Manufacturing Projects. Kogan Page, London.

Brown SL and EISENHARDT KM (1998) Competing on the Edge: Strategy as Structured Chaos. Harvard Business School Press, Boston, MA.

Burnes B (1998) No such thing as. . .a 'one best way' to manage organisational change. Management Decision 34(10): 11-18.

CARrier L (1999) Managing at light speed. IEEE Computer July, 
$107-109$

Crescenzi AD (1989) The dark side of strategic IS implementation, Information Strategy: The Executive Journal Fall, 14-20.

DALE MW (1993) The re-engineering route to business transformation. In The Innovation Challenge (HusseY D, Ed), John Wiley.

DeMarco T (1982) Controlling Software Projects. Yourdon Press, New York, USA.

HaKIM C (1987) Research Design: Strategies and Choice in the Design of Social Research. Allen and Unwin, London.

Ho C-H (1996) Information Technology implementation strategies for manufacturing organizations. International Journal of Operations and Production Management 16(7), 77-100.

Hochstrasser B and Griffiths C (1991) Controlling IT Investment: Strategy and Management. Chapman and Hall, London.

IRANI Z and Love PED (2001) The propagation of technology management taxonomies for evaluating investments in Information Systems. Journal of Management Information Systems 17(3), 161-177.

Irani Z, Hlupic V and Giaglis G (2000) Business process re-engineering: a design perspective. The International Journal of Flexible Manufacturing Systems 12(4), 247-252.

Irani Z, Ezingeard J-N, Grieve RJ and Race P (1999) A case study strategy as part of an information systems research methodology: a critique. The International Journal of Computer Applications in Technology 12(2), 190-198.

Irani Z, EZINGEARD J-N and Grieve RJ (1998) Costing the true costs of IT/IS investments: a focus during management decision making. The Journal of Logistics and Information Management 11(1), 3843.

Irani Z, Ezingeard J-N and Grieve RJ (1997) Integrating the costs of an IT/IS infrastructure into the investment decision making process. The International Journal of Technological Innovation, Entrepreneurship and Technology Management (Technovation) 17(11/12), 695-706.

Johnson J (1995) Chaos: the dollar drain of IT project failures. Application Development Trends 16, 47.

KAPLAN RS (1985) Financial justification for the factory of the future. Working Paper, Harvard Business School, USA.

KeIL M (1994) Managing IT projects for success: re-engineering or better project management?, ICIS panel discussion, Vancouver, 16th December.

Kelly DP and Culleton B (1999) Process improvement for small organisations. IEEE Computer October, 41-47.

\section{About the authors}

Dr Zahir Irani is a Senior Lecturer in the Department of Information Systems and Computing, Brunel University (UK). Having worked for several years as a project manager, Zahir retains close links with industry, and is a non-executive director to a leading engineering company, and consults with organisations such as Shell Petroleum, Glaxo Wellcome, BMW (UK) and Adidas. Dr Irani also evaluates European Union (EU) research proposals that are submitted as part of the fifth framework. Dr Irani serves as a non-executive member to an international academic advisory group for MCB University Press, and is a member of the editorial board of Butterworth Heinemann/Computer Weekly - Professional Information Systems Text Books series.

Dr Zahir Irani leads a multi-disciplinary research group investigating information systems evaluation and integration (ISEIG), where he also supervises a number of $\mathrm{PhD}$ students. $\mathrm{He}$ is a Visiting Scholar to the University of Salford (UK) and a Visiting Professor at Deakin University (Australia). Dr Zahir Irani is the Editor in Chief of the Journal of Logistics and Information Management, and has co-authored a teaching textbook on information systems evaluation as well as writing over 100 internationally refereed papers. He has presented at conferences worldwide, and is internationally known for his scholarly work in the area of information systems evaluation and integration. Dr Irani is on the editorial advisor board of several
Khalifa G, Irani Z, Baldwin LP and Jones S (2000) Evaluating Information Technology with You in Mind. Seventh European Conference on Information Technology Evaluation (ECITE2000), Trinity College Dublin, September 28-29.

KPMG UK (1996). Learning Organisation Benchmarking. http://www.kpmg.co.uk/kpmg/uk/services/manage/learn.html

Longenecker CO, Simonetti JL and Sharkey TW (1999) Why organisations fail: the view from the front-line. Management Decision 37(6), 503-513.

LYYTINEN K and HiRSCHHEIM R (1987) Information systems failurea study and classification of the empirical literature. In Oxford Surveys in Information Technology, vol 4 (ZoRKoczy PI, Ed), pp 257309, Oxford University Press, Oxford, UK.

MerCer D (1999) Organisational futures: unprepared for the surprises to come. Management Decision 37(5), 411-416.

Paulk M, Weber C, Garcia S, Chrissis MB and Bush M (1993) Key Practices of the Capability Maturity Model Version 1.1. Software Engineering Institute, Report CMU/SEI-93-TR-025, Carnegie Mellon University, USA.

Phan DD, Vogel DR and Nunamaker JF JR (1995) Empirical studies in software development projects: field survey and OS/400 survey. Information and Management 28(1), 271-280.

REMENYI D (1991) The formulation and implementation of strategic information systems. Unpublished PhD Thesis, Henley Management College, Brunel University, Uxbridge, UK.

RocKaRT JF (1979) Chief executives define their own data needs. Harvard Business Review 57(2), 81-93.

Tuval Y (1999) Against the Flow. Orion Business Books, London.

WILLCOCKS L (1994) Introduction: of capital importance. In Information Management: The Evaluation of Information Systems Investments (WiLlcocks L, Ed), pp 1-27, Chapman and Hall, London.

WillCOCKS L and MargetTs H (1994) Information managementrisk and information systems: developing the analysis. In Information Management: The Evaluation of Information Systems (WillcocKs L, Ed), pp 207-230, Chapman \& Hall, London.

WIGHT OW (1984) Manufacturing Resource Planning: MRPII. Oliver Wight Ltd, USA.

YIN RK (1994) Case Study Research: Design and Methods. Applied Social Research Methods Series: Volume 5. Sage Publications, USA.

international journals, as well as being co-and-mini-track chair to international conferences. He has guest edited special issue journals that include: IEEE Transactions on Professional Communications, European Journal of Information Systems, International Journal of Technology Management, Information Systems Journal and the International Journal of Flexible Manufacturing Systems. Dr Irani has also received numerous grants and awards from national/international funding bodies: Engineering and Physical Sciences Research Council (EPSRC), Royal Academy of Engineering, Australian Research Council (ARC), Defence Evaluation Research Agency (DERA) and European Commission (EC). Further biographical details can be found at: http://www.brunel.ac.uk/ csstzni/ E-mail: Zahir.Irani@Brunel.ac.uk

Amir M Sharif is a Consultant within the e-Integration group of KPMG Consulting (UK). His role involves providing business advice and technical consultancy across all aspects of Application Development, Technical Architecture and Integration, and IT/e-Business strategy, for many leading national and multinational organisations. Amir obtained his BEng (Hons) in Aeronautical Engineering from City University, London. Mr Sharif has a keen interest in IT/IS evaluation, the application of Artificial Intelligence to information systems 
management, and Knowledge Management within industry. He has published research in these areas in international peerreviewed journals and through presentations at conferences worldwide, and has been a committee member for several national and international journals.

Professor Peter ED Love is an Associate Professor and Director of the Australian Agile Construction Initiative. He has coauthored two books, written over 100 internationally refereed journals and spoken at conferences worldwide in the areas of quality and IT/IS project management. Evidence of his output can be found in numerous international journals, such as: Euro- pean Journal of Information Systems, International Journal of Production Economics, and International Journal of Information Management. In addition, he has guest edited special issue international journals on themes Multi-media Technology, Electronic and Internet Commerce and Supporting Supply Chains through IT/IS. His research in the area of IT/IS has been recognised by the Department of Building and Real Estate at Hong Kong Polytechnic University, as he has been invited on several occasions to attend the department as a Visiting Professor. He also serves on the Editorial Advisory Board of several international journals and conference scientific technical committees. 